\title{
Hong Kong Petroleum Stock Pricing Model
}

\author{
Dr. William Lau \\ Department of Decision Sciences and Managerial Economics \\ The Chinese University of Hong Kong \\ (Received 09 September 2018, accepted 11 April 2019) \\ https://doi.org/10.36224/ijes.120205
}

\section{Introduction}

Under the Efficient Market Hypothesis, market price of a particular stock should reflect its fundamental value. However, there are always exceptional cases. For instance, the stock price of Petrochina (857) has remained at $\$ 1 . x x$ for more than a year, but its price has doubled within a few months just after Warren E. Buffett purchased it.

In this paper, we searched for an appropriate regression model to compare and predict the stock prices of three petroleum-related business enterprise listed in Hong Kong Stock Exchange Market but based in China, which are Sinopec Corp. (386), Petro China Company Limited (857), CNOOC Limited (883). By figuring out the relevant independent factors such as Hang Seng Index, H-Share Index, etc., we formed a relevant regression model to evaluate the current price and to forecast the future price of these stocks.

\section{Literature review}

One of the most common stock valuation models is Discounted-Dividend Model (DDM). However, [1] has criticized DDM had too many restrictive assumptions that it was often unable to be applied in real world, and he has proposed a new model that was more amenable to empirical testing.

$$
\mathrm{V}_{0}=\frac{\mathrm{I}_{0} \mathrm{r}_{0}}{\mathrm{k}}+\mathrm{I}_{0}\left(\frac{\mathrm{r}_{1}-\mathrm{k}}{\mathrm{k}}\right)\left(\frac{\mathrm{g}}{\mathrm{k}-\mathrm{g}}\right)
$$

where $\quad \mathrm{V}_{0}$ is value or price per share

$\mathrm{I}_{0}$ is book value (equity) per share

$\mathrm{R}_{0}$ is the rate of return on $\mathrm{I}_{0}$

$\mathrm{k}$ is the rate of return investors require

$\mathrm{r}_{1}$ is the rate of return the firm will earn on additional increments of equity

$\mathrm{g}$ is the rate of growth of equity

The first portion represents the gross capitalized value of present earnings from existing equity, while the latter represents the value attribute to the net capitalized value from earnings on future increments of invested equity.

Around ten years later, [2] also criticized that the DDM could be subject to significant misinterpretation and misuse. In particular, it was argued that DDM returns maybe on a different scale from actual expected returns. The implications of the scale mismatch 
problem were noted, particularly for interpreting parameters of the dividend discount market line and implementing the information adjustment procedure for portfolio optimization.

We found that [1] proposed model was also subject to the deficiency mentioned by [2] Hence, instead of applying DDM or revising DDM, we would like to build a new model to evaluate the appropriate stock prices by using regression analysis.

In fact, [3] has pointed out that a single-equation regression model for equity valuation would fail to meet reasonable statistical tests of reliability. Specifically, he found that [4] the estimated parameters of the models would not prove consistently significant, [5] the parameters would not exhibit reasonable stability in different crosssection samples, and [6] the parameters would not exhibit stability for the same sample over time. However, since our model aims only at comparing and evaluating a few stocks in a given period of time, [3] criticism may not apply to our case.

[7] found that a company's reported earnings exercised a substantial influence on expected growth rate in corporate earnings. Alternative accounting reporting schemes might bring different expectation to the stockholders in evaluating the stock price. He also stated that the reporting scheme is particular important in the contest of a merger between firms. Since all the companies we evaluated are following the same accounting system in China, we would not take this factor in our model based on the principle of parsimony.

\section{Methodology}

We ran three regression analyses in accordance with the three different petroleum-related business enterprises mentioned. We have selected four factors, i) Hang Seng Index, ii) Hang Seng China Enterprises Index, iii) Nasdaq Composite, iv) Futures Price of Crude Oil, as the independent variables in our analysis. The reasons are as follows:

The increase in popularity of home computing and internet access has brought a whole new world to the fingertips of investors. We believe that share prices can be affected by investors who use technical analysis to drive their investment techniques. Technical analysis, also known as Chartism, is simply the study of past share price movements and stock market index trends, which are then used to forecast how shares and stock markets will behave in future. Chartism tries to identify, for example, trends in a variety of stock market charts. They argue that if the charts show an upward trend, investors should continue buying. If, however, the charts show a downward trend, you should sell. They also look at moving averages, showing changes in the average share price over specific periods, say a month, and employ a range of other studies to predict future share price movements. Index of different exchange has been selected for our study:

\subsection{Heng seng index}

Hang Seng Index (HSI) was started on November 24, 1969, compiled and maintained by HSI Services Limited, which is a wholly-owned subsidiary of Hang Seng Bank, the second largest bank listed in Hong Kong in terms of market capitalization. HSI is a capitalization-weighted stock market index in the Hong Kong Stock Exchange. It is used to record and monitor daily changes of the 33 largest companies of the Hong Kong stock market and as the main indicator of the overall market performance in Hong Kong. These companies represent about $70 \%$ of capitalization of the Hong Kong Stock Exchange. 


\subsection{Hang seng china enterprises index}

The Index, introduced in August 1995, tracks the overall performance of 50 China's stateowned enterprises listed on the Hong Kong Stock Exchange. Full market capitalization of the H-share portion of each of the constitutant company is adopted for the index calculation.

\subsection{NASDAQ composite index}

NASDAQ Composite Index measures all NASDAQ domestic and international based common type stocks listed on The NASDAQ Stock Market. Today the NASDAQ Composite includes over 3,000 companies, more than most other stock market indices. Because it is so broad-based, the Composite is one of the most widely followed and quoted major market indices.

iv) Futures price of crude oil

The price of oil fluctuates quite widely in response to crises or recessions in major economies, because any economic downturn reduces the demand for oil. On the supply side the OPEC cartel uses its influence to stabilise or raise oil prices.

Since the main business is oil refinery, the public do expect the changing price of crude oil should have some influence on the share price of the companies.

\section{Results}

We gathered the 5 years data for our regression analysis. We adopt Stepwise Regression. There are totally 989 values, which is large enough to avoid the over-fitted problem as there are only four independent variables. We analyze each of the petroleum-related business enterprises as follows:

\subsection{Sinopec corp. (386)}

Table 1 : Model summary ${ }^{\mathrm{e}}$

\begin{tabular}{|l|r|r|r|r|r|}
\hline Model & \multicolumn{1}{|c|}{ R } & R Square & $\begin{array}{c}\text { Adjusted R } \\
\text { Square }\end{array}$ & $\begin{array}{c}\text { Std. Error of } \\
\text { the Estimate }\end{array}$ & Durbin-Watson \\
\hline 1 & $.995^{\mathrm{a}}$ & .989 & .989 & .08279 & \\
2 & $.995^{\mathrm{b}}$ & .991 & .991 & .07720 & \\
3 & $.995^{\mathrm{c}}$ & .991 & .991 & .07650 & \\
4 & $.996^{\mathrm{d}}$ & .992 & .991 & .07405 & .178 \\
\hline
\end{tabular}

a. Predictors: (Constant), CHINA INDEX

b. Predictors: (Constant), CHINA INDEX, Crude Oil

c. Predictors: (Constant), CHINA INDEX, Crude Oil, HANG SENG INDEX

d. Predictors: (Constant), CHINA INDEX, Crude Oil, HANG SENG INDEX, NASDAQ INDEX

e. Dependent Variable: SINOPEC 
Table 2: Coefficient ${ }^{\text {a }}$

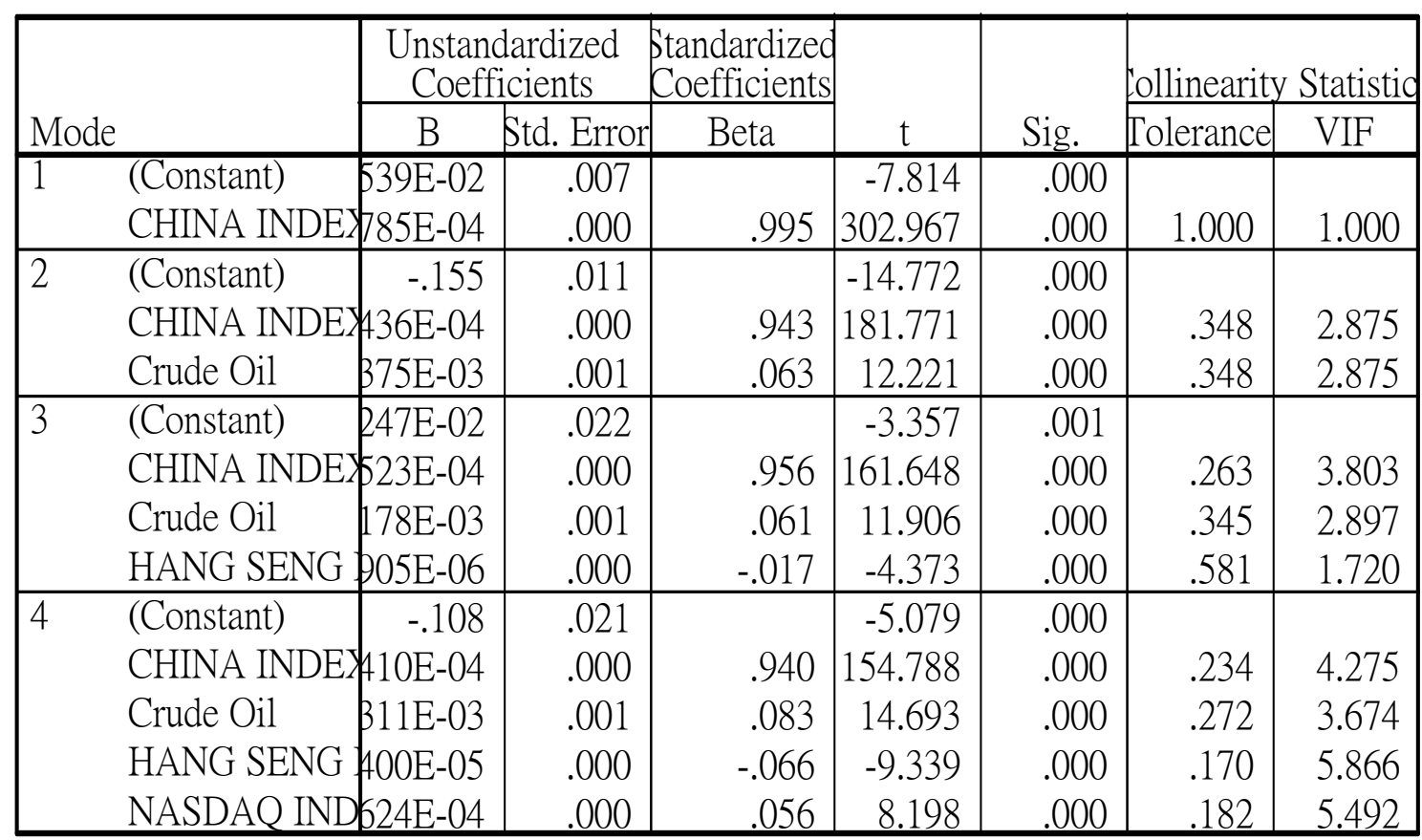

a.Dependent Variable: SINOPEC

The p-values of the F-test is 0.00 , which means that at least one of the independent variables is significant. However, autocorrelation (the computed values of Durbin-Watson statistic of all four models [by running regression four times] are less than $D_{L}$, which means positive autocorrelation) and multicollinearity problems (VIF of some variables are as larger than 5 in model 4) do exist. And we note that Adjusted $\mathrm{R}^{2}$ has neither increased from model 2 to model 3 , nor from model 3 to model 4 . Hence, by the parsimony principle, we would choose model 2 for our prediction purpose. VIF in model 2 has decreased to 2.87 .

$$
\mathrm{Y}=-0.155+0.0006436 \mathrm{X}_{1}+0.006375 \mathrm{X}_{2}
$$

where $\mathrm{Y}$ is the stock price of Sinopec Corp. (386)

$\mathrm{X}_{1}$ is the value of Hang Seng China Enterprises Index

$\mathrm{X}_{2}$ is the Futures Price of Crude Oil

4.2. Petro china company limited (857)

Table 3 : Model summary ${ }^{\mathrm{d}}$

\begin{tabular}{|l|r|r|r|r|r|}
\hline Model & \multicolumn{1}{|c|}{$\mathrm{R}$} & R Square & $\begin{array}{c}\text { Adjusted R } \\
\text { Square }\end{array}$ & $\begin{array}{c}\text { Std. Error of } \\
\text { the Estimate }\end{array}$ & Durbin-Watson \\
\hline 1 & $.990^{\mathrm{a}}$ & .981 & .981 & .15091 & \\
2 & $.994^{\mathrm{b}}$ & .987 & .987 & .12186 & \\
3 & $.994^{\mathrm{c}}$ & .988 & .988 & .12073 & .077 \\
\hline
\end{tabular}

a. Predictors: (Constant), CHINA INDEX

b. Predictors: (Constant), CHINA INDEX, Crude Oil

c. Predictors: (Constant), CHINA INDEX, Crude Oil, NASDAQ INDEX

d. Dependent Variable: PETROCHINA 
Table 4: Coefficient ${ }^{\text {a }}$

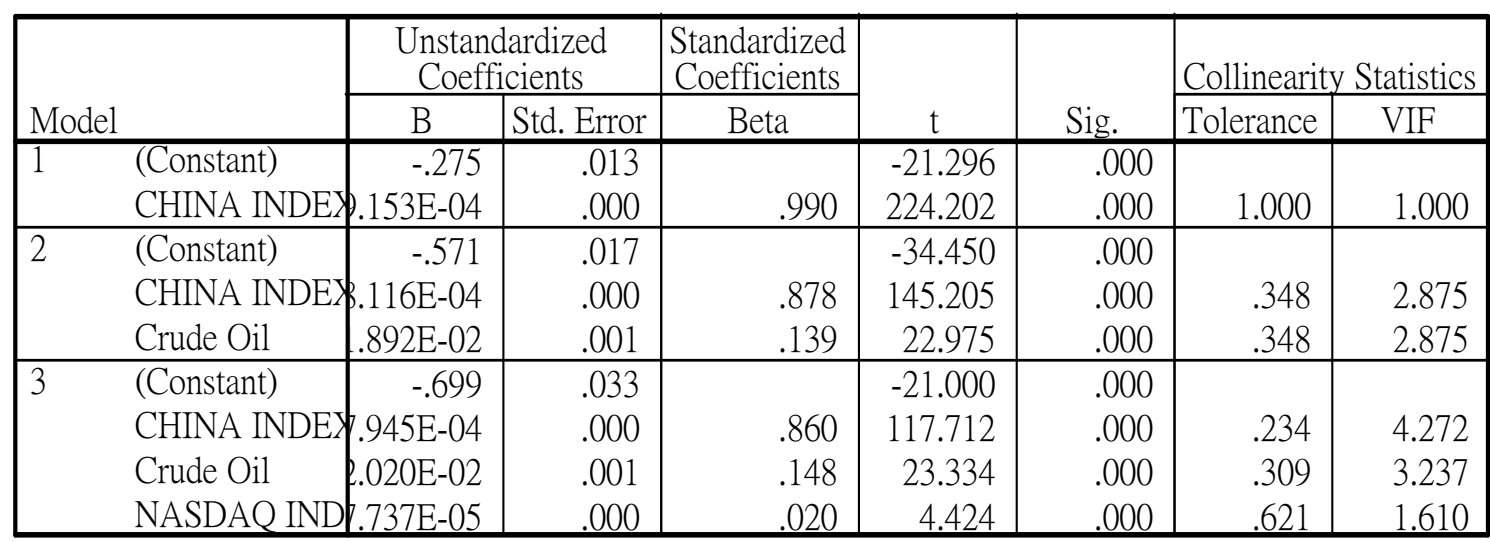

a.Dependent Variable: PETROCHINA

Hang Seng Index is being excluded by the Stepwise Regression analysis. The pvalues of F-test is 0.00 , which means that at least one of the independent variables is significant. However, autocorrelation and multicollinearity problems exist. By the parsimony principle, we choose model 2.

$$
\mathrm{Y}=-0.571+0.0008116 \mathrm{X}_{1}+0.01892 \mathrm{X}_{2}
$$

where $\mathrm{Y}$ is the stock price of Petro China Company Limited (857)

$X_{1}$ is the value of Hang Seng China Enterprises Index

$\mathrm{X}_{2}$ is the Futures Price of Crude Oil

\subsection{CNOOC limited (883)}

Table 5 : Model summary $\mathrm{e}$

\begin{tabular}{|l|r|r|r|r|r|}
\hline Model & $\mathrm{R}$ & R Square & $\begin{array}{c}\text { Adjusted R } \\
\text { Square }\end{array}$ & $\begin{array}{c}\text { Std. Error of } \\
\text { the Estimate }\end{array}$ & Durbin-Watson \\
\hline 1 & $.934^{\mathrm{a}}$ & .872 & .872 & .3105 & \\
2 & $.963^{\mathrm{b}}$ & .928 & .928 & .2337 & \\
3 & $.971^{\mathrm{c}}$ & .942 & .942 & .2090 & .077 \\
\hline
\end{tabular}
a. Predictors: (Constant), CHINA INDEX
b. Predictors: (Constant), CHINA INDEX, Crude Oil
c. Predictors: (Constant), CHINA INDEX, Crude Oil, NASDAQ INDEX
d. Dependent Variable: CNOOC

Table 6 : Coefficient ${ }^{a}$

\begin{tabular}{|c|c|c|c|c|c|c|c|c|}
\hline \multirow{2}{*}{\multicolumn{2}{|c|}{ Model }} & \multicolumn{2}{|c|}{$\begin{array}{c}\text { Unstandardized } \\
\text { Coefficients }\end{array}$} & \multirow{2}{*}{$\begin{array}{c}\text { Standardized } \\
\text { Coefficients } \\
\text { Beta } \\
\end{array}$} & \multirow[b]{2}{*}{$l$} & \multirow[b]{2}{*}{ Sig. } & \multicolumn{2}{|c|}{ Collinearity Statistics } \\
\hline & & $\mathrm{B}$ & Std. Error & & & & Tolerance & VIF \\
\hline & (Constant) & .439 & .027 & & 16.505 & .000 & & \\
\hline & CHINA INDE & $5.902 \mathrm{E}-04$ & .000 & .934 & 82.172 & .000 & 1.000 & 1.000 \\
\hline \multirow[t]{3}{*}{2} & (Constant) & -.241 & .032 & & -7.590 & .000 & & \\
\hline & CHINA INDE $\lambda$ & $1.521 \mathrm{E}-04$ & .000 & .612 & 42.183 & .000 & .348 & 2.875 \\
\hline & Crude Oil & 1. $345 \mathrm{E}-02$ & .002 & .399 & 27.515 & .000 & .348 & 2.875 \\
\hline \multirow[t]{4}{*}{3} & (Constant) & .548 & .058 & & 9.508 & .000 & & \\
\hline & CHINA INDE $\lambda$ & $5.573 \mathrm{E}-04$ & .000 & .754 & 47.698 & .000 & .234 & 4.272 \\
\hline & Crude Oil & $3.556 \mathrm{E}-02$ & .001 & .327 & 23.730 & .000 & .309 & 3.237 \\
\hline & NASDAQ IND & $1.766 \mathrm{E}-04$ & .000 & -.153 & -15.743 & .000 & .621 & 1.610 \\
\hline
\end{tabular}

a. Dependent Variable: CNOOC 
Hang Seng Index is being excluded by the Stepwise Regression analysis. The pvalues of F-test is 0.00 . However, autocorrelation and multicollinearity problems exist. We choose model 3 for it has the highest Adjusted $\mathrm{R}^{2}$. Since our regression model aims at prediction only, so even though individual regression parameters maybe poorly estimated when multicollinearity exists, the overall prediction is still accurate provided we predict $\mathrm{Y}$-value within the range of $\mathrm{X}$-values in our model.

$$
\mathrm{Y}=0.548+0.0005573 \mathrm{X}_{1}+0.03556 \mathrm{X}_{2}+0.0004766 \mathrm{X}_{3}
$$

where $\mathrm{Y}$ is the stock price of CNOOC Limited (993)

$\mathrm{X}_{1}$ is the value of Hang Seng China Enterprises Index

$\mathrm{X}_{2}$ is the Futures Price of Crude Oil

$\mathrm{X}_{3}$ is the value of NASDAQ Composite Index

\section{Discussions and conclusions}

We found that Hang Seng China Enterprises Index and Futures Price of Crude Oil are both significant variables in all three prediction models. $\mathrm{R}^{2}$ are very high in all three models (0.991 for Sinopec Corp., 0.994 for Petro China Company Limited, 0.971 for CNOOC Limited), meaning that the models have very high prediction power. We can therefore compare the market price and the predicted price as a reference for our stock purchase. Ranges of values of the variables in our regression model are as follows:

Stock Price of Sinopec Corp.: HK\$1.00 - HK\$3.75

Stock Price of Petro China Company Limited: HK\$1.29 - HK\$4.85

Stock Price of CNOOC Limited: HK\$1.23 - HK\$4.525

Futures Price of Crude Oil: US\$17.45 - US\$55.17

Value of Hang Seng China Enterprises Index: 1560.55 - 5391.28

Value of NASDAQ Composite Index: 1114.11 - 2313.85

\section{References}

1. Marvin May, "An Investment Opportunities Stock Valuation Model Based on Growth Patterns of Equity", The Journal of Finance, 1971, 26, 993-994.

2. Richard O. Michaud and Paul L. Davis, "Valuation Model Bias and the Scale Structure of Dividend Discount Returns", The Journal of Finance, 1982, 37, 563-573.

3. W. Michael Keenan, "Toward a Positive Theory of Equity Valuation", The Journal of Finance 1968, 23, 197-198.

4. Amir D. Aczel, Complete Business Statistics. (McGraw-Hill), 1999.

5. Kuehn D. A., "Stock Market Valuation and Acquisitions: An Empirical Test of One Component of Managerial Utility", The Journal of Industrial Economics, 1969, 17, 132-144.

6. Gary I. Wakoff, "On Shareholders' Indifference to the Proceeds Price in Preemptive Rights Offerings", The Journal of Financial and Quantitative Analysis, 1973, 8, 835-836.

7. Ramanathan K. V. and Alfred Rappaport, "Size, Growth Rates, and Merger Valuation", The Accounting Review, 1971, 46, 733-745.

8. Haim Ben-Shahar and Abraham Aseher, 1967. The Integration of Capital Budgeting and Stock Valuation: Comment, The American Economic Review, 1967, 57, 209-214.

9. Henry M. K. Mok and Sandy S. M. Chau, 2003. Corporate Performance of Mixed Enterprises, Journal of Business Finance \& Accounting, 2003, 30, 513-537.

10. Linda Elizabeth De Angelo, "Equity Valuation and Corporate Control", The Accounting Review,1990, 65, 93-112.

11. Uri Ben-Zion, "Measures of Risk in the Stock Market and the Valuation of Corporate Stock", The Journal of Finance, 1973, 28, 1043-1044.

12. Zvi Bodie and Robert C. Merton. Finance. (Prentice Hall),2000. 